\title{
Isolation and identification of marine microbial products
}

\author{
Sahar Saleh Mohamed ${ }^{1}$, Sayeda Abdelrazek Abdelhamid ${ }^{1 *}$ and Radwa Hassaan Ali $^{2}$
}

\begin{abstract}
Background: The ocean is one of the world's most important sources of bioactive chemicals in the marine environment. Microbiologists, ecologists, agronomists, taxonomists, and evolutionary biologists have been increasingly interested in marine microbial natural products (MMNPs) in recent decades.

Main body: Diverse marine bacteria appear to get the ability to manufacture an astounding diversity of MMNPS with a wide range of biological actions, including anti-tumor, antimicrobial, and anti-cardiovascular agents according to numerous studies.

Short conclusions: Innovative isolation and culture methodologies, tactics for identifying novel MMNPs via routine screens, metagenomics, genomics, combinatorial biosynthesis, and synthetic biology are all discussed in this review. There is also a discussion of potential issues and future directions for studying MMNPs.
\end{abstract}

Keywords: Bioactive compounds, Marine microbial, Natural products, MMNPs

\section{Background}

The oceans, which cover more than $70 \%$ of the Earth's surface, are not only rich in biodiversity but also a rich source of microorganisms with enormous potential. The maritime environment is home to a broad range of plants, animals, and microbes. Marine microbial communities, which include bacteria, viruses, and other microbes, have various advantages in biotechnological processes. Because almost all of those microbes can produce biochemical products, there is an ongoing need for new chemotherapeutics, particularly novel antibiotics, to address emerging illnesses and drug-resistant pathogens that are posing a serious threat to public health [1]. Over the last few decades, the discovery and development of novel medications from natural products (NPs) have played an important role. NPs are responsible for almost $28 \%$ of new chemical entities and $42 \%$ of anticancer medicines that have been launched to the market [2].

\footnotetext{
* Correspondence: sayeda.abdelrazek@yahoo.com

${ }^{1}$ Microbial Biotechnology Department, Genetic Engineering Division, National Research Centre, Cairo, Egypt

Full list of author information is available at the end of the article
}

Microorganisms, in addition to plants and animals, are a valuable source of novel medicine development. More than 50,000 microbial natural products (MNPs) have been obtained, and they have played a key role in medicine development. The bulk of these have been identified from microorganisms that live on land [3]. Meanwhile, the emergence of severe antibiotic resistance in microbial pathogens including Grampositive methicillin-resistant Staphylococcus aureus (MRSA) and vancomycin-resistant S. aureus (VRSA) is leading to an increase in the number of new diseases and pathogens. The current state of drug research highlights the importance of marine microorganisms as a source of novel secondary metabolites and the possibility to enhance the number of marine NPs in clinical trials [4]. The oceans, in contrast to the terrestrial environment, represent a vast and relatively untapped reservoir of new nanoparticles. Since the 1970s, over 15,000 structurally different NPs with a dizzying array of bioactivities have been discovered in marine habitats [5]. Researchers have been drawn to MMNPs because of their diversity in medication development. Over 30 chemicals

\section{Springer Open}

( ) The Author(s). 2021 Open Access This article is licensed under a Creative Commons Attribution 4.0 International License, which permits use, sharing, adaptation, distribution and reproduction in any medium or format, as long as you give appropriate credit to the original author(s) and the source, provide a link to the Creative Commons licence, and indicate if changes were made. The images or other third party material in this article are included in the article's Creative Commons licence, unless indicated otherwise in a credit line to the material. If material is not included in the article's Creative Commons licence and your intended use is not permitted by statutory regulation or exceeds the permitted use, you will need to obtain permission directly from the copyright holder. To view a copy of this licence, visit http://creativecommons.org/licenses/by/4.0/. 
produced from marine microorganisms, including didemnin B (AplidineTM) and thiocoraline, are being studied in clinical and preclinical trials for the treatment of various malignancies [6]. However, the search for MMNPs has only just begun [6,7]. In this paper, we review the recent advances in MMNP discovery and development, especially addressing two important topics: (i) isolation and cultivation approaches of marine microorganisms and (ii) strategies for the discovery and development of MMNPs.

\section{Isolation and cultivation of marine microorganisms}

The discovery of MMNPs is mostly attributed to marine microbes. Sixteen of the twenty marine anticancer drugs in clinical trials are generated from bacteria [8]. As a result, isolating and cultivating a new marine microbe could be a quick way to find new MMNPs. Microscopy and the fact that overall cell counts are typically three orders of magnitude larger than the number of colonyforming units show this [9]. The majority of microorganisms from the environment (> 99.9\%) do not form colonies on the nutrient-rich agar medium that has been utilized to isolate marine bacteria in the past. This limited culture ability could be attributed to the artificial conditions seen in most culture media, such as the lack of essential nutrients needed for growth [10]. Despite the availability of a variety of molecular methods for analyzing microbial communities, cultivation-based analyses are far from redundant because only the isolation of individual bacterial species in pure culture allows for a comprehensive characterization of physiological properties and a full assessment of application potential (e.g., bioactive compounds) [11]. As a result, developing isolation and cultivation methods is a precondition for studying marine microorganisms in depth.

\section{Isolation of diverse marine microorganism using pretreatment strategies}

Specific groups of marine microorganisms, particularly the less prevalent bacteria, can be isolated using pretreatment procedures. To favor the isolation of specific genera and to improve the recovery of these microorganisms, a variety of pretreatment methods are used including enrichment chemical and physical techniques such as exposure to phenol, dry heat, sucrose-gradient centrifugation, and filtration through cellulose membrane filters [12-16]. These pretreatments reduce or eliminate the possibility of contamination, making it easier to isolate slow-growing marine bacteria. Yamamura et al. [12] established a sucrose centrifugation method for the comparatively high specific isolation of Nocardia, a less abundant Actinomycete, to separate it from other Actinomycete by centrifugation. Nocardia cells were enriched in the $20 \%$ sucrose layer by contrast, larger numbers of Streptomyces spp. were found in the range of $30-50 \%$ sucrose layers and Micromonospora was observed in the range $20-30 \%$ sucrose layers but in relatively low numbers, also Actinoplanes was only recovered from the $10 \%$ sucrose layer. Bredholdt et al. [13] investigated the variety of actinomycetes in the marine sediments of the Trondheim Fjord, Norway, using various pretreatment techniques such as super high-frequency radiation, UV irradiation, extremely high-frequency radiation, and cold shock. In addition to the predominant genera Micromonospora, and Streptomyces representatives of Actinocorallia, Knoellia, Glycomyces, Actinomadura, Nocardia, Nonomuraea, Nocardiopsis, Rhodococcus, Pseudonocardia, and Streptosporangium genera, were isolated from marine. Jensen et al. [14] used 8 selective isolation techniques include dry/ scrape, dry/stamp, dilute/heat, dry/dilute, dilute/heat + dry/stamp, and freeze/dilute to isolate actinomycete from 275 marine samples collected around the Guam island. The most common actinomycetes were discovered, including the seawater-dependent "Salinospora," a new genus of the Micromonosporaceae family. Furthermore, members of two important novel clades linked to Streptomyces spp., MAR2, and MAR3, were grown and suggested to represent new species within the Streptomycetaceae that can be easily cultured using low-nutrient media. Kjer et al. [16] explained in detail the isolation and cultivation procedures for fungi associated with algae, sponges, and mangroves. Marine-derived fungi can also produce a slew of new bioactive secondary metabolites that could be used as innovative therapeutics or plant protection agents.

\section{Selection and design of culture media for the biodiversity of marine microbes}

Nutrients, energy sources, and proper physicochemical conditions are necessary for growth of microorganism. Various bacteria require specific nutrients in specific amounts and types. Most marine microorganisms have specific nutritional (sponge extract [17]) or chemical needs for development (siderophores [18], non-traditional electron donors, electron acceptors, and signal molecules [19]). Bruns et al. [20] employed artificial brackish water with different carbon substrates such as starch, agarose, laminarin, chitin, xylan, and glucose at low concentrations $(200 \mu \mathrm{M}$ each) as the growth medium to improve the cultivation efficiency of bacteria from the Gotland Deep in the central Baltic Sea. In compared to prior research [21], this approach generated much higher culture efficiency in fluid media, up to $11 \%$. Furthermore, at a low concentration of $10 \mu \mathrm{M}$, adding cyclic AMP 
(cAMP), N-oxohexanoyl-DL-homoserine lactone, or N-butyryl homoserine lactone can greatly improve culture performance. The most efficient inducer was cAMP, which resulted in cultivation efficiencies of up to $100 \%$ of total counts of bacteria. Other culture conditions such as medium ionic strength are important to growth of marine microbes. Genus of marine actinomycetes desferrioxamine (Fig. 1a), arenamides, saliniketals, salinosporamide, and arenimycin are examples of beneficial secondary metabolites produced by Salinispora [22-26]. Three species of Salinispora, S. tropica, S. arenicola, and S. pacifica, require a high ionic strength for growth, according to Tsueng et al. [27]. Salinispora has a growth requirement for divalent ions calcium and magnesium, as well as a growth requirement for ionic strength (8.29 to $15.2 \mathrm{mS} / \mathrm{cm}$ ) in both lithium chloride-based and sodium chloride-based environments. S. arenicola has a lower ionic strength growth requirement than $S$. tropica and S. pacifica. They also developed a potassium chloride-based salt formulation containing low sodium concentration $(5.0 \mathrm{mM})$ to support the growth of S. tropica NPS21184 and its production of salinosporamide A (NPI-0052). Although S. tropica does not have a seawater growth requirement, it requires a specific combination of salts to provide a balance of salts and maintains a high enough ionic strength for growth [28].

\section{Innovative cultivation approaches to recover less- cultivable or unculturable marine microbes}

Only around $1 \%$ of bacteria are capable of being cultured, and these are the ones that are not [29], thus finding means to cultivate the uncultured bulk of the microbial world for the discovery of MMNPs is a top priority for microbiologists today. The antitumor chemicals pederin (Fig. 1b), mycalamide A, and onnamide A were found by an uncultivated bacterial symbiont of the marine sponge Theonella swinhoei [30]. Several researches in recent years have shown that by refining traditional methods, several "not-yet-cultured" species may be produced. Slow-growing microbes thrive in nutrient-poor environments and may be inhibited by substrate-rich conventional media [11]. Nutrient-rich culture media may favor the growth of faster-growing microbes at the expense of slow-growing species that always thrive in nutrient-poor environments and may be inhibited by substrate-rich conventional media. As a result, recovering uncultivated microorganisms requires a culture that mimics the natural environment. For example, hitherto uncultivated microorganisms, such as the ubiquitous SAR11 marine bacterio-plankton clade,

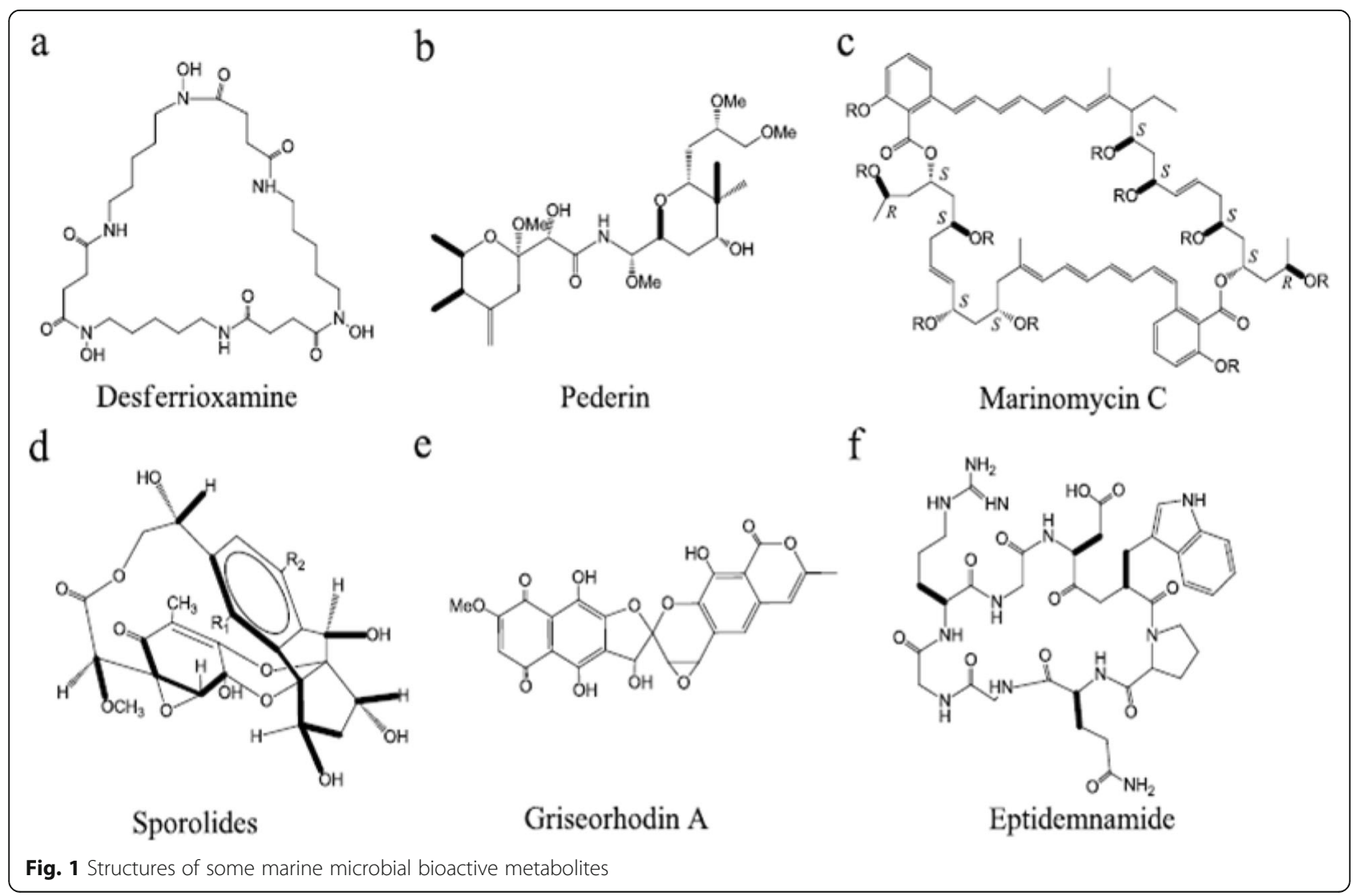


have been cultured in saltwater [31, 32]. Furthermore, hitherto uncultivable microorganisms from various marine habitats have been successfully cultivated using dilute nutrient media techniques [10, 32, 33]. At in situ substrate concentrations, Stephanie et al. [33] identified and grew four new cell lineages belonging to hitherto uncultured or described marine Proteobacteria clades (three orders of magnitude less than common laboratory media). The clades OM43 (subclass), SAR11 (subclass), SAR92 (subclass), and OM60/OM241 (subclass) were shown to be connected to these four distinct cell lineages. Furthermore, under laboratory circumstances, certain germs can only be successfully cultured in the presence of other microorganisms. Growth-stimulating chemicals generated by helper microorganisms are frequently used by unculturable strains. As a result, uncultivable species were frequently given culture supernatants or cell-free extracts from helper strains as growth stimulants [34-37]. In the marine environment, many microorganisms grow slowly; consequently, extended incubation time is required for the cultivation of such microbes at low substrate concentrations in specified media, with the added benefit of minimizing bacterial competition among mixed populations [11]. To separate the primary bacterioplankton lineages in the East Sea, Western Pacific Ocean, Song et al. [32] used modified dilution-to-extinction cultivation with prolonged incubation at low temperature. Extinction cultures of the Roseobacter, SAR11, OM43, and SAR92 clades were isolated after 20 and 24 weeks of plate incubation. Three reviews $[11,29,38]$ have explored the potential causes of unculturability as well as various different ways for cultivating unculturable bacteria despite the fact that many "not-yet-cultured" species can be cultivated, and the molecular processes of unculturability have been discovered, finding new cultivation tactics is still an effective step for all microbiologists and plays a significant role in identifying new species. Various techniques such as high throughput screening (HTS), diffusion chamber system [37, 39], encapsulation method [34, 40], soil substrate membrane system [41-44], filtration method [45], density-gradient centrifugation, extinction dilution [46], and fluorescence-activated cell sorting (FACS) [46] have had a significant impact on recovering as-yet-uncultivated species. Zengler et al. [10] used flow cytometry to detect microdroplets harboring microcolonies after encapsulating cells in gel microdroplets for massively parallel microbial culture under low nutrient flux circumstances. Kaeberlein et al. [39] created a diffusion chamber that allowed substances from the natural environment to pass across a membrane, allowing hitherto uncultivated bacteria to be separated from sea sediment. They discovered that these isolates only established colonies on artificial media when other bacteria were present. Diffusion chambers of this type have also been used in the study of seldom cultivated microorganisms from the sea [37]. The substrate membrane utilized for micro colony development of uncultivated bacteria systems [42] is one of the most recently created, creative techniques. A polycarbonate membrane support and soil extract as a substrate are used in this system. It enables the microculture of novel bacterial strains, the detection of living micro colonies using viability staining, and the micromanipulation of colony separation [41]. Overall, new methodologies and techniques for isolation and cultivation will be required to recover more cultivated and as-yet-uncultivated microbial species in order to uncover structurally distinct chemicals with interesting biological activity.

\section{Discovery and development of MMNPs}

The isolation of new marine microorganisms, as well as the innovation of screening methodologies, encourages the identification and development of novel MMNPs. In this part, five screening methodologies for MMNP discovery and development are discussed: (i) conventional screening, (ii) metagenomics, (iii) genomics, (iv) combinatorial biosynthesis, and (v) synthetic biology. Table 1 provides an overview of the important studies of MMNPs identified using various approaches.

\section{MMNPs discovery via conventional screenings}

Bioactivity-guided screening and gene-guided screening are two of the most common screening approaches. Using the culture supernatant or extract of cell pellet, bioactivity-guided screening can discover activity such as

Table 1 Representative examples of MMNPs discovered by various methods

\begin{tabular}{lllll}
\hline Compounds & Host & Method & Activity & Reference \\
\hline marinomycin & Marinispora sp. CNQ-140 & bioactivity-guided screening & antitumor & [47] \\
medermycin & Streptomyces sp. 16 & gene-guide screening & antimicrobial and antitumor & [48] \\
pederin & uncultured Pseudomonas sp. & metagenomics & antitumor & [30] \\
salinilactam A & Salinospora tropica & genomics & antitumor & {$[25]$} \\
salinosporamide & Salinospora tropica & combinatorial biosynthesis & proteasome inhibitor & [49] \\
XI/X2 & & & & antitumor \\
eptidemnamide & Prochloron spp. & synthetic biology & & [50] \\
\hline
\end{tabular}


antiparasitic, anticancer, antibiotic, antiviral. Marinomycins A-D (Fig. 1c), for example, were isolated from the saline culture of Marinispora sp. CNQ-140 based on significant antibacterial activities (the values of MIC are 0.1-0.6 $\mu \mathrm{M}$ ) against drug-resistant pathogens (MRSA) and impressive and selective cancer cell cytotoxicities (the MIC50 values are $0.2-2.7 \mu \mathrm{M}$ ) against six melanoma cell lines in the National Cancer Institute's NCI-60 cell line panel [47]. Gene-guided screening has been used to look for target genes related with NPs biosynthesis pathways in order to find novel sources of bioactive secondary metabolites including the fragments between ketosynthase and methylmalonyl-CoA transferase of polyketides (PKS) type I [51], dTDP-glucose-4, 6dehydratase (dTGD) gene [48], enediyne PKS ketosynthase gene [52], O-methyltransferase gene [53], P450 monooxygenase gene [54], polyether epoxidase gene [55], 3-hydroxyl-3-methylglutaryl coenzyme A reductase gene [56], and halogenase gene [57]. Gene-based screening, when paired with homology-based searches and phylogenetic analysis, has the highest promise for predicting the generation of novel secondary metabolites carried by isolates or environments. This predictive capability offers a quick and easy way to avoid isolating known compounds or finding strains that produce compounds in a certain structural class [58]. Chen et al. [48] used PCR to explore at the distribution of the dTGD gene and the diversity of putative 6-deoxyhexose $(6 \mathrm{DOH})$ glycosylated compounds in 91 marine sediment-derived bacteria from 48 OTUs and 25 species. The dTGD gene was found in $84 \%$ of the strains, indicating that the $6 \mathrm{DOH}$ biosynthesis pathway is ubiquitous in these marine sediment-derived bacteria. The BLASTp results also revealed that the possible $6 \mathrm{DOH}$ glycosylated molecules had a wide chemical diversity. The findings showed that phylogenetic analysis of the dTGD gene can be used to predict the structure of glycosylated compounds from freshly isolated strains, which can help with chemical purification and structure identification processes including medermycin and chromomycin A3 [48]. In the absence of fully built pathways or genome sequences, gene-guided screening gives a bioinformatics assessment of secondary metabolite biosynthesis potential. This simple and quick prediction, which includes new secondary metabolites or recognized chemicals in the strains, can help speed up the MMNP discovery process by allowing researchers to pick strains for fermentation and chemical investigation (Fig. 2). For the discovery of marine microbial natural products (MMNPs), a combination technique of gene-based

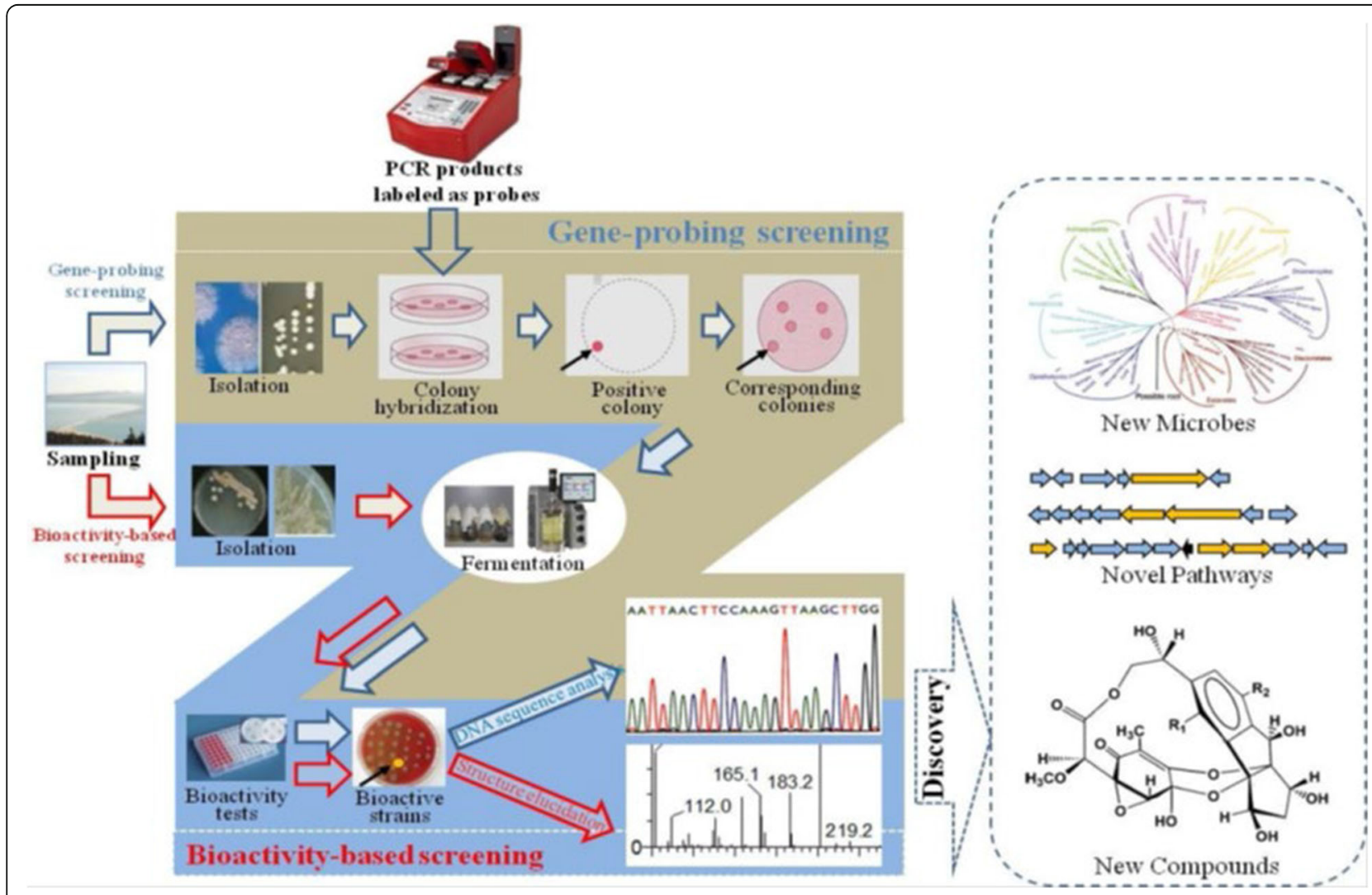

Fig. 2 The combined strategy of gene-based screening and bioactivity-based screening for marine microbial natural products' (MMNPs) discovery 
screening and bioactivity-based screening was used. Due to the drawbacks of bioactivity/gene-guided screening, a combination technique of gene and bioactivity screening (Fig. 2) may be more effective in obtaining useful strains capable of synthesizing novel bioactive chemicals. For 109 bacteria isolated from four South China Sea sponges, Zhang et al. [59] used PCR to screen for nonribosomal peptide synthetase (NRPS) genes. Based on $16 \mathrm{~S}$ rDNA sequences, fifteen bacteria were found to have NRPS genes and were divided into two phyla: Firmicutes (13 of 15) and Proteobacteria (2 of 15). Based on phylogenetic analysis of the conserved domain, the majority of the NRPS fragments (11 of 15) exhibited a $70 \%$ resemblance to their nearest relatives, indicating the uniqueness and diversity of these NRPS genes. The antimicrobial activities of all 15 bacteria with NRPS genes were found, with the majority of them having broad-spectrum activity against fungi and bacteria, indicating the chemical diversity of sponge-associated bacteria's biologically active metabolites and the possible role of bacterial symbiosis in the host's antimicrobial chemical defense [59]. In summary, the combined gene and bioactivity technique will be beneficial in the development of novel MMNPs.

\section{MMNPs discovery via metagenomics}

More than $99 \%$ of bacteria are difficult to cultivate in the lab. The majority of bacteria must therefore be discovered using culture-independent approaches [60]. By extracting complete ambient DNA, metagenomics allows direct access to the genomes of whole environmental microbes. The introduction of eDNA into a suitable host and screening of these enormous eDNA libraries for bioactive clones is an effective technique to access NPs encoded by the genomes of previously uncultured microorganisms [61]. eDNA libraries derived from microbial populations in unusual or unknown conditions are thus significant resources for MMNP discovery $[62,63]$. The finding of novel structures with varied bioactivities, including as violacein, terragines, turbomycins, and indirubin using the metagenomic technique has demonstrated that this technology is a viable option for NP drug development in uncultivable microorganisms [5]. The two primary methodologies for eDNA library screening are function-driven analysis (e.g., bioactivity assay) and sequence-driven analysis (e.g., DNA probe) $[61,62,64]$. The essential genetic components for the intact cluster assembly are identified through sequencebased screening using homologous PCR or clone hybridization [60]. Feng et al. [65] exploited transformation-associated recombination to reassemble two described eDNA clones (called AB185 and AB649) into a complete type II PKS biosynthetic pathway and heterologously expressed in $S$. albus, based on the sequence-driven analysis. C, F, G, and $\mathrm{H}$, four new metabolites fluostatins, were discovered in assembled clones but not in AB649 cultures alone [65]. Furthermore, the creation of a variety of model microbial systems that can act as heterologous hosts for eDNA expression could broaden the NP repertoire. Craig et al. [66] investigated the $\beta$--Proteobacterium Ralstonia metallidurans as a potential model system for eDNA library expression. Cosmids conferring the production of unique pigmented/ antibacterial compounds in $R$. metallidurans clones did not operate in $E$. coli, which was surprising. This innovative technique extracted novel chemicals with a simple biosynthetic scheme, such as patellamide, indigo, and pederin [30]. As a result, a wider range of model hosts will be used to expand the number of metabolites discovered in future metagenomic research. The inability to efficiently acquire complete gene fragments and incompatibility of expression elements such as the promoter in a heterologous host may be limitations of metagenomics. Although it is still too early to draw any conclusions about metagenomics-based MMNP discovery, we believe that rapid advances in synthetic biology, such as large DNA fragment assembly techniques for artificial genome synthesis and synthetic microbial chassis suitable for various classes of MMNP biosynthesis, will greatly aid active expression of the entire DNA cluster.

\section{Mining diverse biosynthetic clusters of MMNPs via genomics strategies}

Because secondary metabolites like NRPS, PKS, and PKS-NRPS hybrids are commonly biosynthesized by large multifunctional synthases that progressively assemble tiny carboxylic acid and amino acid building blocks into their products, genomics has been utilized to MNP identification [25]. With advancements in DNA sequencing and bioinformatics, it is now possible to quickly identify the gene cluster of bioactive chemicals and predict their chemical structure in silico using genomic data. These structural predictions can help with compound purification, structure confirmation, and the identification of new chemical entities [67]. To date, the genome sequence tags (GSTs) probe has effectively discovered over $450 \mathrm{MNP}$ gene clusters using the genome scanning technique [68]. This approach was utilized by Zazopoulos et al. [68] to isolate an enediyne (a potent family of antitumor antibiotics) gene cluster from a range of marine actinomycete strains. A conserved cassette of five gene clusters, including a novel family of PKS, was discovered in a comparative examination of five biosynthetic loci characteristic of enediynes. In all enediynes, the enediyne PKS plays a role in the production of the highly reactive chromophore ring (or "warhead") structure. Actinomycetes have a high prevalence of the enediyne warhead cassette, according to genome 
scanning study. The number of gene clusters involved in NP production is far more than the number of metabolites identified in microorganisms through genome sequencing [69]. Actinomycetes' genome study, for example, reveals a plethora of cryptic gene groups [70-72]. On average, each actinomycete strain appears to have the ability to create around $20 \mathrm{NPs}$, while standard screening regularly only detects about two NPs per strain [69]. The powerful proteasome inhibitor salinosporamide A [73], the unprecedented halogenated macrolides sporolides A and B (Fig. 1d) [74], lymphostin, and salinilactam are among the chemicals generated by S. tropica. By genome sequencing, Udwary et al. [25] identified all secondary metabolic biosynthetic gene clusters in S. tropica CNB-440. The majority of the 17 biosynthetic clusters have never been seen before. This strain has the most diversified polyketide biosynthetic pathways, as well as the greatest proportion of its genome $(9.9 \%)$ dedicated to NP production. Not only has bioinformatic analysis benefited in the structure elucidation of the polyene macrolactam salinilactam A, but it has also aided in the genome assembly of the highly repetitive slm loci [25]. Winter et al. [75] outlined the findings in this field and assessed the field's future prospects. More than 50 actinomycete genomes are being sequenced around the world [76, 77], making genomics more appealing. When a result, as more genome-mining techniques is developed, genomics will become more potent in the discovery of MMNPs.

\section{Diversified MMNPs via combinatorial biosynthesis}

Chemical synthesis presents a problem when it comes to generating derivatives from NPs due to their complicated architectures. Combinatorial biosynthesis is a great approach for increasing the chemical variety of NPs to solve this difficulty. It entails manipulating the biosynthetic clusters of NPs genetically in order to obtain new/altered structures that would be difficult to synthesis using existing approaches. As a result, it is a valuable addition to typical microbial drug discovery strategies. MMNPs' biosynthetic elements differ from those produced from terrestrial sources in that they contain halogenase and other new enzymes. Combinatorial biosynthesis can produce unnatural compounds by heterologous expression of biosynthetic genes from many sources [78]. In The chlorinase SalL halogenates S-adenosyl-l-methionine (SAM) in the biosynthesis of salinosporamide A to form $5^{\prime}$-chloro$5^{\prime}$-deoxyadenosine $\left(5^{\prime}\right.$-CIDA) in a nucleophilic substitution similar to that of the fluorinase in the fluoroacetate producer S. cattleya [79]. SalL's substrates are also bromide and iodide, rather than fluoride. Eustaquio et al. [79] used synthetic 5'-fluoro-5' -deoxyadenosine $\left(5^{\prime}-\mathrm{FDA}\right)$ to make fluorosalinosporamide, a novel salinosporamide derivative, in a salL-knockout mutant of S. tropica that was devoid of salinosporamide A. Moreover, a new shunt in the phenylalanine pathway to L-3-cyclohex-2'-enylalanine (CHA) residue in salinosporamide A (SalX disruption in S. tropica mutant) through combinatorial biosynthesis enabled the generation of not only antiprotealide but also other unnatural salinosporamide derivatives (salinosporamide X1 and salinosporamide X2) with $\mathrm{C} 5$ modifications in the salinosporamide family of potent proteasome inhibitors [49]. Despite the numerous triumphs of combinatorial biosynthesis $[50,80]$, there is a stumbling block in the form of the designed compound's productivity being lower than that of the parent MMNPs. Furthermore, despite the wide variety of possible structural alterations, combinatorial biosynthesis does not yield compound libraries with great diversity [69]. As a result, these issues in combinatorial biosynthesis will most likely be solved within the next decade.

\section{Diversified MMNPs via synthetic biology}

MMNPs accumulate at very low levels in native producers, despite the vast structural diversity in their libraries providing a pharmacological pool for public health. More MMNPs can be generated to enable structural elucidation, activity investigation, and potentially clinical trials, thanks to advancements in microbial cultivation and fermentation technology. Ordinary people, on the other hand, cannot afford the therapeutic cost of MMNPs due to their higher manufacture cost. In addition, a growing number of MMNPs found through genome or environmental DNA sequence mining are awaiting confirmation. With synthetic biology's rapid advancement, it could be a potential technique for improving the production of recognized chemicals or activating silent gene clusters. Because of the rapid advancement of synthetic biology, it may be a potential technique for improving health. The development of genome-wide genetic manipulation techniques such as hierarchical conjugative assembly genome engineering (CAGE) [81] and multiplex automated genome engineering (MAGE) [82] is based on the development of genome-wide genetic manipulation techniques, and synthetic biology can create natural or artificial biosynthetic pathways in the host microorganisms for MMNPs using plentiful genetic resources (e.g., functional genes taken from many sources, controlled regulatory elements $[74,83]$, and synthetic RNA/protein scaffolds [75, 76]). Given the triumphs of synthetic biology, the high yields of erythromycin precursor 6-deoxy-erythronolide B, taxol precursor taxadiene, and artemisinin precursor amorphadiene in surrogate hosts $[77,78]$ are the finest 
examples, indicating its enormous potential for the creation of useful MMNPs. Compatibility between host microbes and synthetic materials of the intended product, including pathway gene expression, enzyme activity, and precursor supply, are essential concerns for host selection in synthetic biology, in addition to efficient DNA manipulation and transfer methods. Although the production of NPs is quite similar in terrestrial and marine microbes, developing marinederived hosts (e.g., marine-derived cyanobacteria, actinomycetes, and fungi) will be useful in the quest for heterologous MMNP expression. Non-essential DNA sections have been removed from genome-minimized microorganisms [81], making them a viable biological chassis for MMNPs. All of the preceding research and methodologies are paving the way for the synthesis of MMNPs through heterologous expression. The use of heterologous production of full NP gene clusters to investigate the role of genes and gene clusters involved in metabolite manufacture is a clever method [79]. At Heron Island, Queensland, Australia, Piel et al. [78] isolated Streptomyces sp. JP95 from the marine ascidian Aplidium lenticulum. The telomerase inhibitor griseorhodin A (Fig. 1e), produced by Streptomyces sp. JP95, is the most heavily oxidized bacterial polyketide known, with a unique epoxyspiroketal moiety that is critical for its activity [78]. The griseorhodin biosynthetic cluster encodes an extraordinary number of functionally distinct oxidoreductases (encoded by 11 different ORFs), which are engaged in the oxidative modification of a polyaromatic tridecaketide precursor via three carbon-carbon bond cleavage. Streptomyces sp. JP95 is surprisingly resistant to foreign DNA introduction via a number of ways, preventing knockout tests to establish that the grh cluster is involved in griseorhodin production. Heterologous expression of the entire grh cluster in S. lividans on a suitable shuttle cosmid is an alternate method. As a result, the S. lividans ZX1 (pMP31a) modified strain can successfully manufacture griseorhodin A and three other similar chemicals. Another successful case is that a new cyclic peptide eptidemnamide (Fig. 1f) was produced by an engineered $E$. coli by replacing the ulithiacyclamide (5)-coding region from patE2 (responsible for heterocyclization of cysteine, serine and threonine residues, and $\mathrm{N}$-terminal to $C$-terminal cyclization to afford the final patellamides) with a wholly artificial construct and expression of the pat cluster (responsible for patellamide biosynthesis) from the obligate cyanobacterial symbionts Prochloron spp., thereby demonstrating for the first time that the whole biosynthetic cluster of MMNPs can be functionally expressed in the surrogate host [50]. Despite the fact that synthetic biology is a new science with much more work to be done on its theory and methodology, there is little question that it will usher in a new era of MMNP development [80].

\section{Conclusion}

Marine microbial natural products (MMNPs) have gotten a lot of interest recently from a variety of sources. Diverse marine bacteria appear to be capable of producing a vast diversity of MMNPs with antimicrobial, antitumor, anti-inflammatory, and anti-cardiovascular properties. MMNPs include metagenomics, genomics, combinatorial biosynthesis, and synthetic biology. A discussion of potential challenges and future options for MMNP research is also included.

\section{Acknowledgements \\ Not applicable}

\section{Authors' contributions}

All authors certify that they have participated sufficiently in contributing to the intellectual content, concept, and writing the manuscript, and all authors have read and approved the manuscript, and ensure that this is the case. R.H.A. collected the material and wrote the review, and S.S.M. formatted the review. S.A.A. (corresponding author) confirms that all listed authors have approved the manuscript before submission, including the names and order of authors, and that all authors receive the submission and all substantive correspondence with editors, as well as the full reviews.

\section{Funding}

Not applicable

\section{Availability of data and materials}

Not applicable

\section{Declarations}

Ethics approval and consent to participate Not applicable

Consent for publication

Not applicable

Competing interests

The authors declare that they have no competing interests.

Author details

${ }^{1}$ Microbial Biotechnology Department, Genetic Engineering Division, National Research Centre, Cairo, Egypt. ${ }^{2}$ Masoud Hospital, Cairo, Egypt.

Received: 30 May 2021 Accepted: 2 October 2021

Published online: 19 October 2021

\section{References}

1. Xiong ZQ, Zhang ZP, Li JH, Wei SJ, Tu GQ (2012) Characterization of Streptomyces padanus JAU4234, a producer of actinomycin X2, fungichromin, and a new polyene macrolide antibiotic. Appl. Environ. Microbiol. 78(2):589-592. https://doi.org/10.1128/AEM.06561-11

2. Newman DJ, Cragg GM (2007) Natural products as sources of new drugs over the last 25 years. J. Nat. Prod. 70(3):461-477. https://doi.org/10.1021/ np068054v

3. Berdy J (2005) Bioactive microbial metabolites. J. Antibiot. 58(1):1-26. https://doi.org/10.1038/ja.2005.1

4. Waters AL, Hill RT, Place AR, Hamann MT (2010) The expanding role of marine microbes in pharmaceutical development. Curr. Opin. Biotechnol. 21(6):780-786. https://doi.org/10.1016/j.copbio.2010.09.013 
5. Li X, Qin L (2005) Metagenomics-based drug discovery and marine microbial diversity. Trends Biotechnol. 23(11):539-543. https://doi.org/10.101 6/j.tibtech.2005.08.006

6. Liu X, Ashforth E, Ren B, Song F, Dai H, Liu M, Wang J, Xie Q, Zhang L (2010) Bioprospecting microbial natural product libraries from the marine environment for drug discovery. J. Antibiot. 63(8):415-422. https://doi.org/1 0.1038/ja.2010.56

7. Newman DJ, Hill RT (2006) New drugs from marine microbes: the tide is turning. J. Ind. Microbiol. Biotechnol. 33(7):539-544. https://doi.org/10.1007/ s10295-006-0115-2

8. Simmons TL, Coates RC, Clark BR, Engene N, Gonzalez D, Esquenazi E, Dorrestein PC, Gerwick WH (2008) Biosynthetic origin of natural products isolated from marine microorganism-invertebrate assemblages. Proc. Natl. Acad. Sci. USA 105(12):4587-4594. https://doi.org/10.1073/pnas.0709851105

9. Jensen PR, Fenical W (1994) Strategies for the discovery of secondary metabolites from marine bacteria: ecological perspectives. Annu. Rev. Microbiol. 48(1):559-584. https://doi.org/10.1146/annurev.mi.48.100194.003015

10. Zengler K, Toledo G, Rappe M, Elkins J, Mathur EJ, Short JM, Keller M (2002) Cultivating the uncultured. Proc. Natl. Acad. Sci. USA 99(24):15681-15686. https://doi.org/10.1073/pnas.252630999

11. Vartoukian SR, Palmer RM, Wade WG (2010) Strategies for culture of "unculturable" bacteria. FEMS Microbiol. Lett. 309(1):1-7. https://doi.org/1 0.1111/j.1574-6968.2010.02000.x

12. Yamamura H, Hayakawa M, limura $Y$ (2003) Application of sucrose-gradient centrifugation for selective isolation of Nocardia spp. from soil. J. Appl. Microbiol. 95(4):677-685. https://doi.org/10.1046/j.1365-2672.2003.02025.x

13. Bredholdt H, Galatenko OA, Engelhardt K, Fjaervik E, Terekhova LP, Zotchev SB (2007) Rare actinomycete bacteria from the shallow water sediments of the Trondheim Fjord, Norway: isolation, diversity and biological activity. Environ. Microbiol. 9(11):2756-2764. https://doi.org/10.1111/j.1462-2920.2 007.01387.x

14. Jensen PR, Gontang E, Mafnas C, Mincer TJ, Fenical W (2005) Culturable marine actinomycete diversity from tropical Pacific Ocean sediments. Environ. Microbiol. 7(7):1039-1048. https://doi.org/10.1111/j.1462-2920.2005. 00785.x

15. Kjer J, Debbab A, Aly AH, Proksch P (2010) Methods for isolation of marinederived endophytic fungi and their bioactive secondary products. Nat. Protoc. 5(3):479-490. https://doi.org/10.1038/nprot.2009.233

16. Abdelmohsen UR, Pimentel-Elardo SM, Hanora A, Radwan M, Abou-El-Ela SH, Ahmed S, Hentschel U (2010) Isolation, phylogenetic analysis and antiinfective activity screening of marine sponge-associated actinomycetes. Mar. Drugs 8(3):399-412. https://doi.org/10.3390/md8030399

17. D'Onofrio A, Crawford JM, Stewart EJ, Witt K, Gavrish E, Epstein S, Clardy J, Lewis K (2010) Siderophores from neighboring organisms promote the growth of uncultured bacteria. Chem. Biol. 17(3):254-264. https://doi.org/1 0.1016/j.chembiol.2010.02.010

18. Kopke B, Wilms R, Engelen B, Cypionka H, Sass H (2005) Microbial diversity in coastal subsurface sediments: a cultivation approach using various electron acceptors and substrate gradients. Appl. Environ. Microbiol. 71(12): 7819-7830. https://doi.org/10.1128/AEM.71.12.7819-7830.2005

19. Bruns A, Cypionka H, Overmann J (2002) Cyclic AMP and acyl homoserine lactones increase the cultivation efficiency of heterotrophic bacteria from the central Baltic Sea. Appl. Environ. Microbiol. 68(8):3978-3987. https://doi. org/10.1128/AEM.68.8.3978-3987.2002

20. Amann Rl, Ludwig W, Schleifer KH (1995) Phylogenetic identification and in situ detection of individual microbial cells without cultivation. Microbiol. Rev. 59(1):143-169. https://doi.org/10.1128/mr.59.1.143-169.1995

21. Asolkar RN, Kirkland TN, Jensen PR, Fenical W (2010) Arenimycin, an antibiotic effective against rifampin- and methicillin-resistant Staphylococcus aureus from the marine actinomycete Salinispora arenicola. J. Antibiot. 63(1): 37-39. https://doi.org/10.1038/ja.2009.114

22. Udwary DW, Zeigler L, Asolkar RN, Singan V, Lapidus A, Fenical W, Jensen PR, Moore BS (2007) Genome sequencing reveals complex secondary metabolome in the marine actinomycete Salinispora tropica. Proc. Natl. Acad. Sci. USA 104(25):10376-10381. https://doi.org/10.1073/ pnas.0700962104

23. Fenical W, Jensen PR (2006) Developing a new resource for drug discovery: marine actinomycete bacteria. Nat. Chem. Biol. 2(12):666-673. https://doi. org/10.1038/nchembio841

24. Tsueng G, Lam KS (2010) A preliminary investigation on the growth requirement for monovalent cations, divalent cations and medium ionic strength of marine actinomycete Salinispora. Appl. Microbiol. Biotechnol. 86(5):1525-1534. https://doi.org/10.1007/s00253-009-2424-7

25. Tsueng G, Lam KS (2008) Growth of Salinispora tropica strains CNB440, CNB476, and NPS21184 in nonsaline, low-sodium media. Appl. Microbiol. Biotechnol. 80(5):873-880. https://doi.org/10.1007/s00253-008-1614-z

26. Pham VH, Kim J (2012) Cultivation of unculturable soil bacteria. Trends Biotechnol. 30(9):475-484. https://doi.org/10.1016/j.tibtech.2012.05.007

27. Piel J, Hui D, Wen G, Butzke D, Platzer M, Fusetani N, Matsunaga S (2004) Antitumor polyketide biosynthesis by an uncultivated bacterial symbiont of the marine sponge Theonella swinhoei. Proc. Natl. Acad. Sci. USA 101(46): 16222-16227. https://doi.org/10.1073/pnas.0405976101

28. Rappe MS, Connon SA, Vergin KL, Giovannoni SJ (2002) Cultivation of the ubiquitous SAR11 marine bacterioplankton clade. Nature 418(6898):630-633. https://doi.org/10.1038/nature00917

29. Song J, Oh HM, Cho JC (2009) Improved culturability of SAR11 strains in dilutionto-extinction culturing from the East Sea West Pacific Ocean. FEMS Microbiol. Lett. 295(2):141-147. https:/doi.org/10.1111/j.1574-6968.2009.01623.x

30. Connon SA, Giovannoni SJ (2002) High-throughput methods for culturing microorganisms in very-low-nutrient media yield diverse new marine isolates. Appl. Environ. Microbiol. 68(8):3878-3885. https://doi.org/10.1128/A EM.68.8.3878-3885.2002

31. Bae JW, Rhee SK, Park JR, Kim BC, Park YH (2005) Isolation of uncultivated anaerobic thermophiles from compost by supplementing cell extract of Geobacillus toebii in enrichment culture medium. Extremophiles 9(6):477485. https://doi.org/10.1007/s00792-005-0467-y

32. Nichols D, Lewis K, Orjala J, Mo S, Ortenberg R, O'Connor P, Zhao C, Vouros $P$, Kaeberlein T, Epstein SS (2008) Short peptide induces an "uncultivable" microorganism to grow in vitro. Appl. Environ. Microbiol. 74(15):4889-4897. https://doi.org/10.1128/AEM.00393-08

33. Kaeberlein T, Lewis K, Epstein SS (2002) Isolating "uncultivable" microorganisms in pure culture in a simulated natural environment. Science 296(5570):1127-1129. https://doi.org/10.1126/science.1070633

34. Ben-Dov E, Kramarsky-Winter E, Kushmaro A (2009) An in situ method for cultivating microorganisms using a double encapsulation technique. FEMS Microbiol. Ecol. 68(3):363-371. https://doi.org/10.1111/j.1574-6941.2009. 00682.x

35. Ferrari BC, Gillings MR (2009) Cultivation of fastidious bacteria by viability staining and micromanipulation in a soil substrate membrane system. Appl. Environ. Microbiol. 75(10):3352-3354. https://doi.org/10.1128/AEM.02407-08

36. Ferrari BC, Winsley T, Gillings M, Binnerup S (2008) Cultivating previously uncultured soil bacteria using a soil substrate membrane system. Nat. Protoc. 3(8):1261-1269. https://doi.org/10.1038/nprot.2008.102

37. Hahn MW, Stadler P, Wu QL, Pockl M (2004) The filtration-acclimatization method for isolation of an important fraction of the not readily cultivable bacteria. J. Microbiol. Methods 57(3):379-390. https://doi.org/10.1016/j. mimet.2004.02.004

38. Wang Y, Hammes F, Boon N, Chami M, Egli T (2009) Isolation and characterization of low nucleic acid (LNA)-content bacteria. ISME J. 3(8):889902. https://doi.org/10.1038/ismej.2009.46

39. Kwon HC, Kauffman CA, Jensen PR, Fenical W (2006) Marinomycins A-D, antitumor-antibiotics of a new structure class from a marine actinomycete of the recently discovered genus "Marinispora". J. Am. Chem. Soc. 128(5): 1622-1632. https://doi.org/10.1021/ja0558948

40. Chen F, Lin L, Wang L, Tan Y, Zhou H, Wang Y, He W (2011) Distribution of dTDP-glucose-4,6-dehydratase gene and diversity of potential glycosylated natural products in marine sediment-derived bacteria. Appl. Microbiol. Biotechnol. 90(4):1347-1359. https://doi.org/10.1007/s00253-011-3112-y

41. McGlinchey RP, Nett M, Eustaquio AS, Asolkar RN, Fenical W, Moore BS (2008) Engineered biosynthesis of antiprotealide and other unnatural salinosporamide proteasome inhibitors. J. Am. Chem. Soc. 130(25):78227823. https://doi.org/10.1021/ja8029398

42. Donia MS, Hathaway BJ, Sudek S, Haygood MG, Rosovitz MJ, Ravel J, Schmidt EW (2006) Natural combinatorial peptide libraries in cyanobacterial symbionts of marine ascidians. Nat. Chem. Biol. 2(12):729-735. https://doi. org/10.1038/nchembio829

43. Ayuso-Sacido A, Genilloud O (2005) New PCR primers for the screening of NRPS and PKS-I systems in actinomycetes: detection and distribution of these biosynthetic gene sequences in major taxonomic groups. Microb. Ecol. 49(1):10-24. https://doi.org/10.1007/s00248-004-0249-6

44. Liu W, Ahlert J, Gao Q, Wendt-Pienkowski E, Shen B, Thorson JS (2003) Rapid PCR amplification of minimal enediyne polyketide synthase cassettes 
leads to a predictive familial classification model. Proc. Natl. Acad. Sci. USA 100(21):1 1959-11963. https://doi.org/10.1073/pnas.2034291100

45. Wang H, Liu N, Xi L, Rong X, Ruan J, Huang Y (2011) Genetic screening strategy for rapid access to polyether ionophore producers and products in actinomycetes. Appl. Environ. Microbiol. 77(10):3433-3442. https://doi.org/1 0.1128/AEM.02915-10

46. Khan ST, Izumikawa M, Motohashi K, Mukai A, Takagi M, Shin-Ya K (2010) Distribution of the 3-hydroxyl-3-methylglutaryl coenzyme A reductase gene and isoprenoid production in marine-derived Actinobacteria. FEMS Microbiol. Lett. 304(1):89-96. https://doi.org/1 0.1111/j.1574-6968.2009.01886.x

47. Hornung A, Bertazzo M, Dziarnowski A, Schneider K, Welzel K, Wohlert SE, Holzenkampfer M, Nicholson GJ, Bechthold A, Sussmuth RD et al (2007) A genomic screening approach to the structure-guided identification of drug candidates from natural sources. ChemBioChem 8(7):757-766. https://doi. org/10.1002/cbic.200600375

48. Gontang EA, Gaudencio SP, Fenical W, Jensen PR (2010) Sequence-based analysis of secondary-metabolite biosynthesis in marine actinobacteria. Appl. Environ. Microbiol. 76(8):2487-2499. https://doi.org/10.1128/AEM.02 852-09

49. Zhang W, Li Z, Miao X, Zhang F (2009) The screening of antimicrobial bacteria with diverse novel nonribosomal peptide synthetase (NRPS) genes from South China sea sponges. Mar. Biotechnol. 11(3):346-355. https://doi. org/10.1007/s10126-008-9148-z

50. Singh J, Behal A, Singla N, Joshi A, Birbian N, Singh S, Bali V, Batra N (2009) Metagenomics: concept, methodology, ecological inference and recent advances. Biotechnol. J. 4(4):480-494. https://doi.org/10.1002/biot.200800201

51. Brady SF (2007) Construction of soil environmental DNA cosmid libraries and screening for clones that produce biologically active small molecules. Nat. Protoc. 2(5):1297-1305. https://doi.org/10.1038/nprot.2007.195

52. Banik JJ, Brady SF (2010) Recent application of metagenomic approaches toward the discovery of antimicrobials and other bioactive small molecules. Curr. Opin. Microbiol. 13(5):603-609. https://doi.org/10.1 016/j.mib.2010.08.012

53. Lorenz P, Eck J (2005) Metagenomics and industrial applications. Nat. Rev. Microbiol. 3(6):510-516. https://doi.org/10.1038/nrmicro1161

54. Daniel R (2005) The metagenomics of soil. Nat. Rev. Microbiol. 3(6):470-478. https://doi.org/10.1038/nrmicro1160

55. Feng Z, Kim JH, Brady SF (2010) Fluostatins produced by the heterologous expression of a TAR reassembled environmental DNA derived type II PKS gene cluster. J. Am. Chem. Soc. 132(34):1 1902-11903. https://doi.org/10.1 021/ja104550p

56. Craig JW, Chang FY, Brady SF (2009) Natural products from environmental DNA hosted in Ralstonia metallidurans. ACS Chem. Biol. 4(1):23-28. https:// doi.org/10.1021/cb8002754

57. Zhang L, An R, Wang J, Sun N, Zhang S, Hu J, Kuai J (2005) Exploring novel bioactive compounds from marine microbes. Curr. Opin. Microbiol. 8(3): 276-281. https://doi.org/10.1016/j.mib.2005.04.008

58. Zazopoulos E, Huang K, Staffa A, Liu W, Bachmann BO, Nonaka K, Ahlert J, Thorson JS, Shen B, Farnet CM (2003) A genomics-guided approach for discovering and expressing cryptic metabolic pathways. Nat. Biotechnol. 21(2):187-190. https://doi.org/10.1038/nbt784

59. Luzhetskyy A, Pelzer S, Bechthold A (2007) The future of natural products as a source of new antibiotics. Curr. Opin. Investig. Drugs 8(8):608-613

60. Bentley S, Chater K, Cerdeno-Tarraga AM, Challis G, Thomson N, James K, Harris D, Quail M, Kieser H, Harper D (2002) Complete genome sequence of the model actinomycete Streptomyces coelicolor A3 (2). Nature 417(6885): 141-147. https://doi.org/10.1038/417141a

61. Ōmura S, Ikeda H, Ishikawa J, Hanamoto A, Takahashi C, Shinose M, Takahashi Y, Horikawa H, Nakazawa H, Osonoe T (2001) Genome sequence of an industrial microorganism Streptomyces avermitilis: deducing the ability of producing secondary metabolites. Proc. Natl. Acad. Sci. USA 98(21): 12215-12220. https://doi.org/10.1073/pnas.211433198

62. Ikeda H, Ishikawa J, Hanamoto A, Shinose M, Kikuchi H, Shiba T, Sakaki Y, Hattori M, Ōmura S (2003) Complete genome sequence and comparative analysis of the industrial microorganism Streptomyces avermitilis. Nat. Biotechnol. 21(5):526-531. https://doi.org/10.1038/nbt820

63. Feling RH, Buchanan GO, Mincer TJ, Kauffman CA, Jensen PR, Fenical W (2003) Salinosporamide A: a highly cytotoxic proteasome inhibitor from a novel microbial source, a marine bacterium of the new genus Salinospora. Angew. Chem. Int. Ed. 42(3):355-357. https://doi.org/10.1002/anie.200390115
64. Buchanan GO, Williams PG, Feling RH, Kauffman CA, Jensen PR, Fenical W (2005) Sporolides A and B: structurally unprecedented halogenated macrolides from the marine actinomycete Salinispora tropica. Org. Lett. 7(13):2731-2734. https://doi.org/10.1021/ol050901i

65. Winter JM, Behnken S, Hertweck C (2011) Genomics-inspired discovery of natural products. Curr. Opin. Chem. Biol. 15(1):22-31. https://doi.org/10.101 6/j.cbpa.2010.10.020

66. Xiong ZQ, Wang Y (2012) Draft genome sequence of the marine Streptomyces sp. strain AA1529, isolated from the Yellow Sea. J. Bacteriol 194:5474-5475

67. Xiong ZQ, Wang Y (2012) Draft genome sequence of marine-derived Streptomyces sp. strain AA0539, isolated from the Yellow Sea, China. J. Bacteriol 194:6622-6623

68. Li A, Piel J (2002) A gene cluster from a marine Streptomyces encoding the biosynthesis of the aromatic spiroketal polyketide griseorhodin A. Chem. Biol. 9(9):1017-1026. https://doi.org/10.1016/S1074-5521(02)00223-5

69. Eustaquio AS, Moore BS (2008) Mutasynthesis of fluorosalinosporamide, a potent and reversible inhibitor of the proteasome. Angew. Chem. Int. Ed. 47(21):3936-3938. https://doi.org/10.1002/anie.200800177

70. Piel J (2006) Combinatorial biosynthesis in symbiotic bacteria. Nat. Chem. Biol. 2(12):661-662. https://doi.org/10.1038/nchembio 1206-661

71. Isaacs FJ, Carr PA, Wang HH, Lajoie MJ, Sterling B, Kraal L, Tolonen AC, Gianoulis TA, Goodman DB, Reppas NB, Emig CJ, Bang D, Hwang SJ, Jewett MC, Jacobson JM, Church GM (2011) Precise manipulation of chromosomes in vivo enables genome-wide codon replacement. Science 333(6040):348533. https://doi.org/10.1126/science.1205822

72. Wang HH, Isaacs FJ, Carr PA, Sun ZZ, Xu G, Forest CR, Church GM (2009) Programming cells by multiplex genome engineering and accelerated evolution. Nature 460(7257):894-898. https://doi.org/10.1038/nature08187

73. Alper H, Fischer C, Nevoigt E, Stephanopoulos G (2005) Tuning genetic control through promoter engineering. Proc. Natl. Acad. Sci. USA 102(36): 12678-12683. https://doi.org/10.1073/pnas.0504604102

74. Pfleger BF, Pitera DJ, Smolke CD, Keasling JD (2006) Combinatorial engineering of intergenic regions in operons tunes expression of multiple genes. Nat. Biotechnol. 24(8):1027-1032. https://doi.org/10.1038/nbt1226

75. Dueber JE, Wu GC, Malmirchegini GR, Moon TS, Petzold CJ, Ullal AV, Prather KL, Keasling JD (2009) Synthetic protein scaffolds provide modular control over metabolic flux. Nat. Biotechnol. 27(8):753-759. https://doi.org/10.1038/ nbt.1557

76. Delebecque CJ, Lindner AB, Silver PA, Aldaye FA (2011) Organization of intracellular reactions with rationally designed RNA assemblies. Science 333(6041):470-474. https://doi.org/10.1126/science.1206938

77. Zhang H, Boghigian BA, Pfeifer BA (2010) Investigating the role of native propionyl-CoA and methylmalonyl-CoA metabolism on heterologous polyketide production in Escherichia coli. Biotechnol. Bioeng. 105(3):567-573. https://doi.org/10.1002/bit.22560

78. Martin VJ, Pitera DJ, Withers ST, Newman JD, Keasling JD (2003) Engineering a mevalonate pathway in Escherichia coli for production of terpenoids. Nat. Biotechnol. 21(7):796-802. https://doi.org/10.1038/nbt833

79. Ichinose K, Ozawa M, Itou K, Kunieda K, Ebizuka Y (2003) Cloning, sequencing and heterologous expression of the medermycin biosynthetic gene cluster of Streptomyces sp. AM-7161: towards comparative analysis of the benzoisochromanequinone gene clusters. Microbiology 149(7):16331645. https://doi.org/10.1099/mic.0.26310-0

80. Wang J, Xiong Z, Meng H, Wang Y, Wang Y (2012) Synthetic biology triggers new era of antibiotics development. Subcell. Biochem. 64:95-114. https://doi.org/10.1007/978-94-007-5055-5_5

81. Sowell SM, Norbeck AD, Lipton MS, Nicora CD, Callister SJ, Smith RD, Barofsky DF, Giovannoni SJ (2008) Proteomic analysis of stationary phase in thmarine bacterium "Candidatus Pelagibacter ubique". Appl. Environ. Microbiol. 74(13):4091-4100. https://doi.org/10.1128/AEM.00599-08

82. Beygmoradi A, Homaei A (2017) Marine microbes as a valuable resource for brand new industrial biocatalysts. Biocatalysis. Agric. Biotechnol. 11:131-152

83. Xiong ZQ, Wang JF, Hao YY, Wang Y (2013) Recent Advances in the Discovery and Development of Marine Microbial Natural Products. Mar. Drugs. 11:700-717

\section{Publisher's Note}

Springer Nature remains neutral with regard to jurisdictional claims in published maps and institutional affiliations. 